\title{
Implementation of a health-related quality of life questionnaire for children and adolescents with celiac disease
}

\author{
Mercedes Pico, B.S., ${ }^{a}$ and María Florencia Spirito, B.S. ${ }^{a}$
}

\begin{abstract}
Introduction. Measuring health-related quality of life inpatients with celiac disease allows a comprehensive approach.

Objective. To assess the implementation and sensitivity to change of the Argentine version of the CDDUX disease-specific questionnaire to measure health-related quality of life in children and adolescents.

Methods. Descriptive, observational, longitudinal and prospective study. Participants were 8 to 18 year old children and adolescents with celiac disease, their parents or legal guardians and their gastroenterologists. The CDDUX questionnaire was used to assess health-related quality of life, and sensitivity to change was evaluated using the variation in the score obtained on two different occasions and a scale of change perception from the patient's and his/her parent's standpoint. The questionnaire implementation was appraised using a strength and weakness form completed by patients, parents and gastroenterologists.
\end{abstract}

Results. The first interview was conducted among 118 child/parent dyads who completed the CDDUX and recorded their experience; 102 completed the questionnaire on two occasions. Total scores were higher the second time $(p=0.009$ and 0.003 , respectively). There was consistency between the perception of changeexpressed by the child / adolescent and the father/ mother, and the difference in the CDDUX score obtained at different consultations $(p<0.001)$. Standardized effect size: 0.52 for children/adolescents, and 0.45 for parents. A $64 \%$ agreement was observed among the opinions of children/ adolescents and their parents' opinion (kappa 0.20 ), and a $51 \%$ agreement was found among them and their gastroenterologists (kappa 0.10) in terms of change between consultations (better, the same, or worse). Gastroenterologists also recorded their experience with the CDDUX. They agreed that it was satisfactory and useful.

a. B.S. in Nutrition. Hospital de Pediatría "Prof. Dr. Juan P. Garrahan."

E-mail Address:

Mercedes Pico, B.S.: mercedespico@yahoo. com.ar

Conflict of Interest: None.

Received: 03-04-2013 Accepted: 07-24-2013 onstrated test-retest stability and sensitivity to change. Differentopinions were obtained regarding change in children/adolescents health-related quality of life, with a better agreement among children/adolescents and their parents than among them and their physicians. The CDDUX questionnaire has been accepted by children/adolescents, their parents and gastroenterologists. Key words: quality oflife, children/adolescents, celiac disease, CDDUX, sensitivity to change.

http:/ /dx.doi.org/10.5546/aap.2014.eng.19

\section{INTRODUCTION}

The relevance of including children as subjects, whose points of view are listened to and appraised during consultation, is gaining momentum in pediatric research. The paradigm is changing with a focus on children's daily life from their own perspective because they now have a role in the process of well-being measurement and follow-up.

Health-related quality of life (HRQoL) is the most common indicator used to assess individuals' well-being in relation to their health. Shumaker and Naughton defined HRQoL as "...the subjective evaluation of how health status, health care and health promotion influence an individual's capability to sustain a performance level to carry on their most important daily activities and that impact his/her general well-being...". This definition is based on the individual's perception of his/her own health status; it is also a subjective and multidimensional concept. ${ }^{3,4}$

In chronic conditions, quality of life measurement provides additional information for making decisions in clinical practice and it is useful to detect situations which may go unseen with the traditional approach, thus allowing to improve care or propose alternative strategies so as to enhance treatment compliance. ${ }^{5-7}$

A systematic review of HRQoL instruments in pediatrics showed that most had acceptable reliability and validity results, but few assessed their test-retest stability and sensitivity to change. The test-retest stability measures the degree of answer repeatability by the same individual collected in two or more occasions, allegedly with no changes in their 
health status. ${ }^{8}$ The sensitivity to the change of an instrument is the capacity this instrument has to detect changes in quality of life, through score modifications, when such changes have taken place. $^{9}$

For this reason, it is interesting to encourage longitudinal studies or clinical trials that use HRQoL instruments to follow-up their patients over time. ${ }^{10}$

Implementing an HRQoL instrument in clinical practice requires an evaluation of the process to detect situations that may interfere with its use and to develop approach strategies. It is also important to establish if, once the instrument is applied, it is capable of detecting changes throughout patients' follow-up.

Celiac disease (CD) is a disorder whose physical involvement is improved shortly after starting a diet therapy; it is then when the assessment of psychosocial aspects becomes greatly relevant. Such diet has to be followed for life and implies social restrictions and alterations that could affect a child's quality of life and impact his/her treatment compliance. ${ }^{11-15}$

With the purpose of having a tool that allows to approach the difficulties in HRQoL faced by children and adolescents with CD, we have adapted and validated the CDDUX diseasespecific questionnaire according to international guidelines, which showed an adequate validity and reliability and requires little completion time: 4 minutes in average. ${ }^{16-19}$

The objective of this research was to assess the implementation and sensitivity to change of the Argentine version of the CDDUX disease-specific questionnaire.

\section{Hypothesis}

- It is plausible to implement the CDDUX questionnaire in clinical practice.

- The perception of changes observed by patients and their parents between two consultations is reflected in the CDDUX score and shows that it is preliminary capable of being sensitive to change.

\section{POPULATION AND METHODS}

Descriptive, observational, longitudinal and prospective study conducted at the Hospital de Pediatría "Prof. Dr. Juan P. Garrahan" between July $1^{\text {st }}, 2010$ and June $30^{\text {th }}, 2011$ within the context of the celiac disease interdisciplinary service made up of pediatric gastroenterologists and nutritionists.
The study included children and adolescents aged 8 to 18 years old, diagnosed with celiac disease confirmed by intestinal biopsy, who had been under treatment for at least 6 months and with no acute concomitant conditions affecting their health.

Children/adolescents or parents who were not able to understand the questionnaire and form and children/adolescents with a different chronic disease that required other dietary restrictions were excluded. Recruiting was performed consecutively. The sample was estimated in relation to the plausibility of obtaining it in the served population.

Participating gastroenterologists were members of the celiac disease care team and who received previous training on how to understand and interpret the CDDUX questionnaire.

Ethical considerations: a signed informed consent was obtained from parents or legal guardians, together with the child/adolescent's assent to participate.

The protocol was approved on June $4^{\text {th }}, 2010$ by the Ethics and Research Committee of Hospital "Prof. Dr. Juan P. Garrahan."

\section{Primary Outcome Variables}

Health-related quality of life: measured with the CDDUX. The questionnaire includes 12 items grouped into 3 sub-scales: "Having celiac disease" (3 items), "Communication" (3 items) and "Diet" (6 items). HRQoL was scored using a 1 to 100 point scale and coded using a 5 point Lickert scale. Higher values indicate a better quality of life (range: 0-100; 1-20: very bad, 21-40: bad, 4160: neutral, 61-80: good, 81-100: very good). The total score is the sum of each item score divided by the number of items.

The CDDUX questionnaire was completed by children, adolescents and parents before seeing the gastroenterologist, and results were reported to the physician as supplementary information to the consultation. At the end of the first visit, the gastroenterologist indicated if he/she had ordered any therapeutic intervention based on the CDDUX results and any observation made (referral to other interdisciplinary team professionals, nutritionist, psychologist, clinician, participation in group meetings with other celiac patients, etc.).

Sensitivity to change: evaluated by the variation in the CDDUX score obtained in two different occasions (during outpatient follow-up and with an interval of at least 3 months). A perception of 
change scale was used to assess if such variation actually reflected all changes occurred.

Perception of change: studied using a closed scale with the following categories: better, the same, or worse as an answer to the question related to the child/adolescent's quality of life (as per the aspects assessed in the CDDUX) compared to the previous consultation. This scale was completed by children/adolescents, their parents and gastroenterologists in the second consultation so as to evaluate consistency among opinions.

Experience with the CDDUX administration: measured using a data collection form prepared by the authors with yes-no close-ended questions and an open question regarding strengths and difficulties with its implementation in order to gather information on the use of the CDDUX from children/adolescents, parents or legal guardians, and gastroenterologists standpoint. In the first consultation, children and parents answered the form after completing the CDDUX, while the gastroenterologists answered it once the consultation had ended.

\section{Secondary Outcome Measures}

- Patient age in years.

- Sex.

- Socio-economic level (not poor-poor-destitute): as per INDEC's access to the basic food basket.

- Current status of the condition (asymptomatic or symptomatic): asymptomatic: no clinical signs nor physical symptoms typical of celiac disease.

- Compliance with a gluten-free $\operatorname{diet}($ compliance or non compliance): compliance: if no dietary transgressions were detected in the clinical interview by the B.S. in Nutrition, with a 5-year experience in $C D$, nor in lab results (negative anti-transglutaminase antibodies in a period shorter than 6 months).

\section{Statistical Analysis}

Results of gastroenterologists and families opinions are expressed as answer percentages, and CDDUX scores as mean value and standard deviation.

The presence and direction of changes in the mean total scores of the CDDUX were assessed using the $t$ test for paired samples corresponding to the different times the questionnaire was administered and, in turn, according to the scale of change perceived by the patient and his/her father/mother.
Sensitivity to change was evaluated as per the standardized effect size (SES: score delta/standard deviation from baseline score), regarding a SES higher than 0.20 as relevant. ${ }^{19,20}$

In addition, consistency among patients' opinions and those of their parents and physicians was evaluated using kappa statistics.

According to the data obtained, it is possible to retrospectively infer that the study had an $80 \%$ power (beta error 0.20 ) to detect a difference between the CDDUX baseline score and the score attained the second time.

For analysis purposes, a value of $p<0.05$ was considered significant.

The SPSS 15.0 statistical software for Windows was used.

\section{RESULTS}

A total of 118 child/adolescent-parent dyads were included in the assessment of questionnaire implementation because they completed the form and also the CDDUX. Out of them, 102 child/ adolescent-parent dyads completed the CDDUX a second time and the scale of change perception at a subsequent consultation, therefore making up the sample used to assess sensitivity to change. Sixteen patients were lost because they did not attend their second consultation in the research period. No patients refused to take part.

Participating gastroenterologists were 5 members of the interdisciplinary team ( 3 staff gastroenterologists and 2 residents).

The analysis of the questionnaire's sensitivity to change included 102 cases who completed the CDDUX in two occasions and allowed to explore the occurrence of modifications in the scores and if such modifications were correlated with the perception of change expressed by the child/ adolescent and his/her parent or legal guardian.

Of the 102 children/adolescents, $39.2 \%(n=40)$ were boys and $60.8 \%(n=62)$, girls. Their clinical and socio-economic characteristics are detailed in Table 1. During the first administration of the questionnaire, only 2 children had gastrointestinal symptoms; all were asymptomatic at the time of the second administration. Between $73 \%$ and $77 \%$ referred compliance with a gluten-free diet.

The mean interval between the first and second administrations was 9 months, with a minimum of 3 months and a maximum of 21 months.

The CDDUX total score obtained by children/ adolescents and their parents was higher the second time when compared to the first 
administration, and it was statistically significant in both groups (Table 2).

The results of the first CDDUX led to some intervention in $32.4 \%(n=33)$ of the 102 cases, and this group had overall lower scores than those who did not require any intervention: 58.93 (SD 11.05 ) versus 71.03 (SD 13.45). With the second administration, scores were 65.34 (SD 12.99) and 73.05 (SD 13.13), respectively. The average score variation was 6.41 points and 3.01 points in the intervention and no intervention groups, respectively.

Consistency was observed in the perception expressed by the patient and his/her parent and the difference observed in the scores obtained in the first and second CDDUX administrations; results were significant in those who indicated a change.

The standardized effect size was 0.52 in children/adolescents, and 0.45 in parents (Table 3).

It is worth noting that there was only one report of "feeling worse," with a mean score difference of -16.66 in the patient's CDDUX.

Figure 1 shows the frequency at which parents, children/adolescents and physicians perceived a change in the patient's condition (better, the same, worse) between consultations; most patients and parents perceived an improvement, while most gastroenterologists perceived their condition was the same.

The analysis of agreement among the patients' opinions and that of their parents' and of their physicians' showed a $64 \%$ agreement among patients and parents (kappa 0.20) and an even lower agreement $(51 \%)$ with their doctors (kappa $0.10)$.

Tables 4 and 5 show the opinions of children/ adolescents, parents and gastroenterologists. Most patients and their parents agreed in that the questionnaire was satisfactory and useful because it helped them express things that would not otherwise been voiced during consultation and that the gastroenterologist should know. In addition, half of the respondents indicated that completing the questionnaire made them think of things they had not thought of before. Almost all gastroenterologists considered that the completion of the questionnaire by patients did not interfere with the process of care nor affected the development of the consultation; in turn, they agreed that results provided important information and allowed them to detect certain aspects that required an action to be taken.

TABLE 1. Clinical and socio-economic characteristics of patients at the time of the first and second administrations of the CDDUX questionnaire

\begin{tabular}{|c|c|c|c|c|}
\hline Characteristics & & First administration & Second administration & $p$ value \\
\hline $\begin{array}{l}\text { Current status } \\
\text { of the condition }\end{array}$ & Asymptomatic & $99 \%(n=100)$ & $100 \%(n=102)$ & 0.57 \\
\hline $\begin{array}{l}\text { Compliance with } \\
\text { a gluten-free diet }\end{array}$ & Yes & $73.3 \%(\mathrm{n}=74)$ & $77.5 \%(n=79)$ & 0.40 \\
\hline Socio-economic level* & $\begin{array}{c}\text { Not poor } \\
\text { Poor/destitute }\end{array}$ & $\begin{array}{l}77.5 \%(n=79) \\
22.6 \%(n=23)\end{array}$ & $\begin{array}{l}82 \%(\mathrm{n}=82) \\
18 \%(\mathrm{n}=18)\end{array}$ & $\begin{array}{l}0.47 \\
0.38\end{array}$ \\
\hline
\end{tabular}

* Poverty line as per INDEC's calculation of access to the basic food basket.

TABLE 2. Mean and standard deviation of the CDDUX total score according to children/adolescents and parents at the first and second times the questionnaire was administered

\begin{tabular}{|c|c|c|c|c|}
\hline & $\begin{array}{l}\text { First administration } \\
\text { (102) }\end{array}$ & $\begin{array}{l}\text { Second administration } \\
(\mathbf{1 0 2 )}\end{array}$ & $\begin{array}{l}\text { Difference } \\
x(95 \% \mathrm{CI})\end{array}$ & $p$ value \\
\hline $\begin{array}{l}\text { Children's total score } \\
\text { X (SD) }\end{array}$ & $67.12(14)$ & 71.23 (13.65) & +4.11 & 0.009 \\
\hline $\begin{array}{l}\text { Parents' total score } \\
\text { X (SD) }\end{array}$ & 60.63 (13.6) & $64.44(13.56)$ & +3.80 & 0.003 \\
\hline
\end{tabular}


FIGURE 1. Change in the patient's condition (better, the same, worse) between the two consultations according to the perception of the children/adolescent, parent and gastroenterologist responsible for care

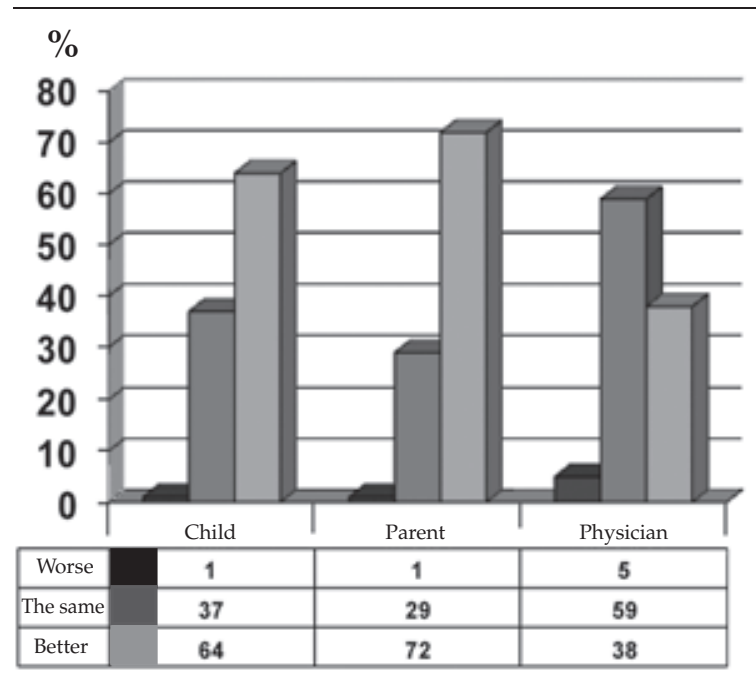

\section{DISCUSSION}

The Argentine version of the CDDUX went through a transcultural adaptation and validation process. This research has allowed us to explore the CDDUX implementation and sensitivity to change.

Although patients' characteristics between the first and second administrations were greatly similar, the CDDUX results showed differences: scores were significantly higher the second time.

The analysis of the sensitivity to change of the CDDUX indicated that score modifications revealed changes in the patient's condition; the questionnaire demonstrated test-retest stability (no changes in the scores of those who indicated no changes in the studied period) and sensitivity to change, with a standardized effect size of 0.52 for children/adolescents and 0.45 for parents, and can be considered relevant as per the sensitivity to change parameter assessment described by

TABLE 3. Presence and direction of changes in the CDDUX mean scores between the different questionnaire administrations with the scale of change perceived by children/adolescent and parents/legal guardians as reference

\begin{tabular}{|c|c|c|c|c|c|c|}
\hline Questionnaire & $\begin{array}{l}\text { erception } \\
\text { change }\end{array}$ & $\begin{array}{l}\text { Mean value of first } \\
\text { administration (SD) }\end{array}$ & $\begin{array}{l}\text { Mean value of second } \\
\text { administration (SD) }\end{array}$ & $\begin{array}{l}\text { Mean delta value } \\
\text { of differences (SD) }\end{array}$ & $p$ value ${ }^{*}$ & SES** \\
\hline \multirow{2}{*}{$\begin{array}{l}\text { Children/adolescents' } \\
\text { total score }\end{array}$} & Yes & $67.89(13.45)$ & 74.91 (12.59) & 7.02 (14.67) & $<0.001$ & 0.52 \\
\hline & No & $65.76(15.02)$ & 64.77 (13.17) & $-0.99(16.20)$ & 0.71 & \\
\hline \multirow{2}{*}{$\begin{array}{l}\text { Parents' total } \\
\text { score }\end{array}$} & Yes & $60.17(13.24)$ & $66.13(13.46)$ & $5.95(13.22)$ & $<0.001$ & 0.45 \\
\hline & No & $61.77(14.65)$ & $60.16(13.09)$ & $-1.60(10.59)$ & 0.42 & \\
\hline
\end{tabular}

* $t$ test paired with an 0.05 alpha.

** Standardized effect size higher than 0.2.

TABLE 4. Results obtained with the questionnaire implementation form completed by children/adolescents and parents/legal guardians

\begin{tabular}{|c|c|c|c|c|}
\hline \multirow[t]{2}{*}{ Question } & \multicolumn{2}{|c|}{ Children/adolescents $(n=117)$} & \multicolumn{2}{|c|}{ Parents $(\mathrm{n}=118)$} \\
\hline & Yes $(\%)$ & No $(\%)$ & Yes $(\%)$ & No $(\%)$ \\
\hline $\begin{array}{l}\text { Did it take you too long to answer } \\
\text { the questionnaire? }\end{array}$ & 17.1 & 82.9 & 9.3 & 90.7 \\
\hline Did it bother you to complete the questionnaire? & 2.6 & 97.4 & 1.7 & 98.3 \\
\hline $\begin{array}{l}\text { Did it make you think of things } \\
\text { you have not thought of before? }\end{array}$ & 52.1 & 47.9 & 57.3 & 42.7 \\
\hline $\begin{array}{l}\text { Do you think it helped you express things } \\
\text { that nobody would have asked you otherwise? }\end{array}$ & 71.8 & 28.2 & 85.6 & 14.4 \\
\hline $\begin{array}{l}\text { Do you think it is important that the } \\
\text { doctor knows the aspects approached } \\
\text { by the questionnaire? }\end{array}$ & 94.9 & 5.1 & 96.6 & 3.4 \\
\hline
\end{tabular}


TABLE 5. Results obtained with the questionnaire implementation form completed by gastroenterologist

\begin{tabular}{|c|c|c|}
\hline \multirow[t]{2}{*}{ Question } & \multicolumn{2}{|c|}{ Gastroenterologist $(n=118)$} \\
\hline & Yes $(\%)$ & No $(\%)$ \\
\hline Did the questionnaire interfere with the process of care? & 6.8 & 93.2 \\
\hline Did the questionnaire impact the development of the consultation? & 2.5 & 97.5 \\
\hline Did results provide relevant information? & 96.6 & 3.4 \\
\hline $\begin{array}{l}\text { Based on the results, did you detect any aspect } \\
\text { that you believe requires some action? }\end{array}$ & 55.9 & 44.1 \\
\hline $\begin{array}{l}\text { Do you agree with systematically including the questionnaire } \\
\text { in your consultation? }\end{array}$ & 99.2 & 0.8 \\
\hline
\end{tabular}

authors such as Pane and Solans in their reviews of health-related quality of life questionnaires..$^{10,20}$

Based on the results, it is suggested that this instrument is capable of detecting changes in the quality of life of children/adolescents with celiac disease that cannot be observed at a clinical level.

Children/adolescents, their parents and gastroenterologists had different perceptions. There was greater agreement among children/ adolescents and parents than among children/ adolescents and gastroenterologists, which is consistent with the observations of other investigations that evaluated such aspects. ${ }^{21-23}$

Differences in the perception of quality of life highlight the importance of considering children's perspective regarding their health without leaving parents' perception out, thus providing a comprehensive view. Parents usually lack first-hand information about, for example, their children's experience at school or in social interactions. Disagreement among parents and their children could be capitalized as a source of information helpful to approach possible conflictive situations or emotional factors that would go unnoticed. Such disagreement was observed in both healthy subjects and patients with psychiatric disorders, migraines, inflammatory bowel disease, abdominal pain, juvenile arthritis, cancer, etc. ${ }^{24}$

It has been argued that discrepancies observed in the reports made by children and their parents or legal guardians may be a valid reflection of each respondent's perspective, not just a matter of inaccuracy or bias. ${ }^{24}$

Based on this, and given the scarce number of categories and disease prevalence, results on agreement among parents, children and physicians should be carefully appraised.

The Dutch version of the CDDUX question- naire did not analyze the experience with its implementation nor sensitivity to change; therefore, it was not possible to compare our results with the original questionnaire.

Given that the patients taking part in this study had a middle and low socio-economic level, celiac patients with higher resources were not represented in the study, which is a challenge for those working with these patients.

The CDDUX is an accepted instrument and has been considered useful by children, parents and physicians.

Implementing questionnaires such as the CDDUX can allow health care professionals to become aware of emotional and social integration aspects that could affect treatment adherence and, in turn, to assess patient changes over time.

\section{CONCLUSIONS}

- Clinical characteristics were similar at the different consultations, but the CDDUX mean values showed differences.

- The questionnaire demonstrated test-retest stability and sensitivity to change.

- Children/adolescents, parents and gastroenterologists had different perspectives of change in the children/adolescents' quality of life between the first and the second administration of the CDDUX, with greater agreement among patients and parents than among patients and physicians.

- The CDDUX proved to be an instrument accepted by children, parents and gastroenterologists.

\section{Acknowledgments}

To Susana Rodríguez, M.D. and Mariana Roizen, M.D., for their continuous guidance and advice throughout the research process. 
To Adriana Bottero, M.D. and the gastroenterologists members of the Celiac Disease Interdisciplinary Care Team for their selfless participation and collaboration with the investigation conduct.

\section{REFERENCES}

1. Mosteiro Díaz P, Somoano García O, Málaga Guerrero S, Riaño Galán I. Calidad de vida en niños y adolescentes con problemas crónicos de salud. Tipica, Boletín Electrónico de Salud Escolar 2010;6(2):250-6.

2. Mason J, Danby S. Children as experts in their lives: Child Inclusive Research. Child Ind Res 2011;4:185-9.

3. Shumaker S, Naughton M. The international assesment of elath related quality of life: a theoretical perspective. En: Shumaker S, Berson R (ed). The international assessment of health related quality of life: Theory, translation, measurement and analysis. Oxford: Rapid Communications; 1995.

4. Bullinger, M. Quality of life: Definition, conceptualization and implications: a methologistis view. Theor Surg 1991;6: 143-8.

5. Urzúa, A.Calidad de vida relacionada a la salud:Elementos conceptuales. Rev Med Chile 2010; 138:358-65.

6. Guyatt GH, Ferrans CE, Halyard MY, Revicki DA, et al. Exploration of the Value of Health-Related Quality-ofLife information from Clinical Research and into Clinical Practice. Mayo Clinic Proc 2007;82(10):1229-39.

7. Rajmil JL, Roizen M, Urzúa A. Calidad de Vida y Salud en la Infancia y la Adolescencia. Boletín Electrónico de Salud Escolar 2010;6(2):244-9.

8. Rajmil L, Estrada MD, Herdmana M, Serra-Suttona V, et al. Calidad de vida relacionada con la salud (CVRS) en la infancia y la adolescencia: revisión de la bibliografía y de los instrumentos adaptados en España. Gac Sanit 2001;15 (Supl. 4):34-43.

9. Consiglio E, Belloso WH. Nuevos indicadores clínicos. La calidad de vida relacionada con la salud. Medicina (B. Aires) 2003; 63(2):172-8.

10. Pane S, Solans M, Gaite L, Serra-Sutton V, et al. Document d'Avaluació. Instrumentos de calidad de vida relacionada con la salud en la edad pediátrica. Revisión sistemática de la literatura: actualización. Barcelona: Agencia d'Avaluació de Tecnologia i Recerca Mèdiques, enero de 2006.

11. Mearin ML. Celiac disease among children and adolescents. Curr Probl Pediatr Adolesc Health Care 2007;37(3):86-105.

12. Olssoon C, Lyon P, Hörnell A, Ivarsson A, Sydner YM. Food that makes you different: The stigma experienced by adolescents with celiac disease. Qual Health Res 2009;19(7);976-84.
13. Roma E, Roubani A, Kolia E, Panayiotou J, et al. Dietary compliance and life style of children with coeliac disease. J Hum Nutri Diet 2010;23(2):176-82.

14. Hopman E, Koopman HM, Wit JM, Mearin ML. Dietary compliance and health-related quality of life in patients with coeliac disease. Eur J Gastroenterol Hepatol 2009;21(9):105661.

15. van Koppen EJ, Schweizer JJ, Csizmadia CG, Krom Y, et al. Long-term health and quality-of-Life. Consequences of mass screening for childhood celiac disease: A 10-Year Follow-up Study. Pediatrics 2009; 123(4): e582-8.

16. Van Doorn RK, Winkler LMF, Zwinderman KH, Mearin ML,Koopman HM. The CDDUX: A disease-specific healthrelated quality of life questionnaire for children with Celiac Disease. J Pediatr Gastroenterol Nutr 2008; 47(2):147-52.

17. Beaton D, Bombardier C, Guillemin F, Ferraz M. Guidelines for the process of cross-cultural adaptation of self-report measures. Spine (Phila Pa 1976) 2000;25(24):3186-91.

18. Pico M, Spirito MF. Adaptación transcultural del CDDUX: Versión española-argentina de un cuestionario de calidad de vida relacionada a la salud específico para niños con enfermedad celíaca. Medicina Infantil 2009;16:387-93.

19. Pico M, Spirito MF, Roizen M. Calidad de vida en niños y adolescentes con enfermedad celíaca: Versión argentina del cuestionario específico CDDUX. Acta Gastroenterol Latinoam 2012;42(1):12-9.

20. Solans M,PaneS, Estrada MD, Serra-Sutton V, et al. HealthRelated Quality of Life Measurement in Children and Adolescents: A Systematic Review of Generic and DiseaseSpecific Instruments. Value Health 2008:11(4):742-64.

21. Roizen M, Figueroa C, Salvia L y miembros del Comité de Calidad de Vida y Salud. Calidad de vida relacionada con la salud en niños con enfermedades crónicas: comparación de la visión de los niños, sus padres y sus médicos. Arch Argent Pediatr 2007;105(4):305-13.

22. Eiser C, Morse R. Can parents rate their child's health related quality of life? Results of a systematic review. Qual Life Res 2001;10(4): 347-57.

23. Janse AJ, Uiterwaal CS, Gemke RJ, Kimpen JL, Sinnema G. A difference in perception of quality of life in chronically ill children was found between parents and pediatrician. J Clin Epidemiol 2005;58(5):495-502.

24. Ellert U, Ravens-Sieberer U, Erhat M, Kurth BM. Health and Determinants of agreement between self-reported and parent-assessed quality of life for children in Germany. Results of the German Health Interview and Examination Survey for Children and Adolescents (KiGGS). Health Qual Life Outcomes 2011; 9:102. 


\section{Annex 1. CDDUX questionnaire implementation form Patient version}

Patient identification:

Date:

Question

Yes

No

Did it take you too long to answer the questionnaire?

Did it bother you to complete the questionnaire?

Did it make you think of things you have not thought of before?

Do you think it helped you express things that nobody would have asked you otherwise?

Do you think it is important that the doctor knows your questionnaire answers so as to help you?

Do you have any comment, opinion or suggestion about this experience? 


\section{Annex 2. CDDUX questionnaire implementationform Father/mother/legal guardian version}

Patient identification:

Date:

Question

Yes

No

Did it take you too long to answer the questionnaire?

Did it bother you to complete the questionnaire?

Did it make you think of things you have not thought of before?

Do you think it helped you express things that would not have been considered during the consultation otherwise?

Do you think it is important that the doctor knows the aspects approached by the questionnaire so as to help your child?

Do you have any comment, opinion or suggestion about this experience? 


\section{Annex 3. CDDUX implementation form Gastroenterologist version}

Date:

Patient identification:

Doctor identification:

Question

Yes

No

Do you think administering the CDDUX interfered with the patient care process?

Did the questionnaire affect the fluent development of the consultation?

Did questionnaire results provide relevant information to you?

Based on the results, did you detect any aspect that you believe requires some action?

If you answered Yes, which of the following actions did you take?

- Enquire about the negative aspects that you observed.

- Refer the patient to a ...................(nutritionist/psychologist/

clinician/social worker) to investigate problem areas in depth.

- Another action:.

Do you think this questionnaire can be systematically included in your consultation?

Do you have any comment, opinion or suggestion about this experience? 